\title{
A SIMPLE FORMULA FOR MIXING ANY GRADE OF ALCOHOL DESIRED.
}

E. W. Berger.

Let $\mathrm{P}$ represent the grade per cent. of the alcohol on hand, $\mathrm{P}^{\prime}$ the grade per cent. required, $v$ the number of volumes of water to be added to one volume of $\mathrm{P}$ to make alcohol $\mathrm{P}^{\prime}$ and $\mathrm{x}$ the number of volumes of $\mathrm{P}$ that we desire to change to $\mathrm{P}^{\prime}$. Then $\frac{\mathrm{Px}}{\mathrm{x}+\mathrm{vx}}=\mathrm{P}^{\prime}$. This gives us (1) $\mathrm{P}^{\prime} \mathrm{v}=\mathrm{P}-\mathrm{P}^{\prime}$, and (2) $\mathrm{v}=\frac{\mathrm{P}-\mathrm{P}^{\prime}}{\mathrm{P}^{\prime}}$. Of these, (1) gives us the pharmaceutical rule quoted by Professor Schaffner in his "Labratory Outlines for General Botany": "Take of the grade at hand as many volumes as the number of the per cent. you wish to make, then add to this enough volumes of pure water to make the total number of volumes agree with the number of the per cent. at hand." And (2) may be translatee into words as follows:-Rule: To find the number of volumes (v) of water to be added to one volume of the grade per cent. (P) on hand, to make alcohol of the grade per cent. $\mathrm{P}^{\prime}$, divide the difference between the number $(\mathrm{P})$ denoting the grade per cent. on hand and the number $\left(\mathrm{P}^{\prime}\right)$ denoting the grade per cent. required, by the latter number $\left(\mathrm{P}^{\prime}\right)$. Or, which is simpler, $\mathrm{v}=\frac{\mathrm{P}-\mathrm{P}^{\prime}}{\mathrm{P}^{\prime}}$.

Professor Irving Hardesty in "Neurological Technique" approximates the above formula (2), and if he had worked it out 
differently and simplified it, he would have arrived at the same results with me. As it is, he gives the reader, not a simple formula, but a table. His work came to my knowledge after I had worked out and presented my formula before the Biological Club and the same has been useful to me only in suggesting a simplification of the equation used for my starting point.

Biological Hall, Ohio State University. 